\title{
Prevalence of Problem Drug Use and Injecting Drug Use in Luxembourg: A Longitudinal and Methodological Perspective
}

\author{
Alain Origer \\ Ministry of Health, Directorate of Health, Luxembourg; \\ PhD Student at the Integrative Research Unit on Social and Individual Development (INSIDE), University of \\ Luxembourg, Walferdange, Luxembourg
}

\section{Key Words}

Drug dependence surveillance systems $\cdot$ Prevalence

estimation $\cdot$ Epidemiology $\cdot$ Methodology $\cdot$ Public health

\begin{abstract}
Background: To estimate the prevalence of problem drug use (PDU) and injecting drug use (IDU) in Luxembourg and analyze trends between 1997 and 2009. To assess the feasibility of prevalence estimations based on drug use surveillance systems. Methods: Serial multi-method PDU/IDU prevalence estimations based upon capture-recapture, Poisson regression, multiplier and back-calculation methods. Comparative analysis of methods and assessment of their robustness to variations of external factors. Results: National PDU and IDU prevalence rates were estimated at $6.16 / 1,000$ (95\% Cl $4.62 / 1,000$ to $7.81 / 1,000)$ and $5.68 / 1,000(95 \% \mathrm{Cl}$ $4.53 / 1,000$ to $6.85 / 1,000$ ) inhabitants aged $15-64$ years, respectively. Absolute prevalence and prevalence rates of PDU increased between 1997 and 2000 and declined from 2003 onwards, whereas IDU absolute prevalence and prevalence rates witnessed an increasing trend between 1997 and 2007. Conclusions: Drug use surveillance systems can be valuable instruments for the estimation and trend analysis of drug misuse prevalence given multiple methods are applied that rely on serial and representative data from different sources and different settings, control multiple counts and build
\end{abstract}

\section{KARGER}

Fax +4161306 1234

E-Mail karger@karger.ch

www.karger.com
(C) 2012 S. Karger AG, Basel

$1022-6877 / 12 / 0186-0288 \$ 38.00 / 0$

Accessible online at:

www.karger.com/ear upon standardized and sustained data collection routines. The described institutional contact indicator revealed to be a useful tool in the context of PDU/IDU prevalence estimations and thus contributes to enhancing evidence-based drug policy planning.

Copyright $\odot 2012$ S. Karger AG, Basel

\section{Introduction}

There is a series of reasons why it may be important to know the size of a population showing drug use or misuse in a given area, such as gathering knowledge on its composition and its distribution within the general population and the willingness to affect its prevalence.

Different techniques exist to estimate the extent of drug use. Also, researchers and stakeholders want these techniques to be valid, reliable, reproducible and cost-effective at best. Summarily, direct and indirect methods may be applied. Indirect estimation techniques tend to build upon existing data and their mutual relationship in order to estimate the number of non-observed cases in a given population. The latter include capture-recapture techniques [1-8], benchmark-multiplier methods [1, 9-11], the truncated Poisson method [1, 12, 13], and the multivariate indicator method [14-19]. However, none of currently known methods is considered to be the gold 
standard since they all rely on a series of assumptions and limitations [20].

A first reason for this refers to data sources and data settings. Methods to estimate drug prevalence may rely on various data such as provided by routine drug use surveillance or monitoring systems, by cross-sectional studies or by more or less representative surveys. In case drug use reporting systems do provide data for prevalence estimations, one has to bear in mind that these are by definition selective as they generally gather information on drug use from services in contact with drug users [21]. As such, they merely include cases that come to the attention of those institutions, thus representing only a variable share of the target population.

Additionally, in the context of drug prevalence estimations, drug use surveillance systems predominantly relying on drug treatment data, also present serious limitations [22] such as possible delays between onset of drug use and first treatment demand [23], variable availability and accessibility of treatment facilities, exclusion of outof-treatment subpopulations and possible lack of control mechanisms to avoid multiple counting [24].

Previous research does suggest favoring a multisource approach (e.g. in- and out-of-treatment settings) [22, 23], multi-method study designs $[6,20,25,26]$ and crosschecking indirect trend indicators $[23,27]$. This said, there appears to be a lack of a formal and appropriate framework to combine various instruments, methods and data to optimize the validity of drug prevalence estimates other than simply look for their concordance and to assess the extent to which they converge to a plausible estimate $[26,28]$.

In the light of these constraints, the Luxembourg drug use surveillance system (RELIS), established in 1995, was built upon the methodological assumption that data exclusively from drug treatment settings may not provide an accurate picture of problem drug use (PDU) as these notably exclude out-of-treatment users whose drug use has generated conflicts with law enforcement only. Hence, to approach the genuine heterogeneity of the drug misuse phenomenon, RELIS routinely compiles data from all existing specialized in- and out-oftreatment sources, in- and outpatient service sources $(n=7)$, low threshold agencies $(n=2)$, psychiatric departments of general hospitals $(n=5)$, substitution treatment program $(n=1)$, prison $(n=1)$ and law enforcement registers $(n=2)$. Also, RELIS relies on the 'institutional contact indicator' as an alternative to the more commonly used 'treatment demand indicator' [23] and does not primarily apply case definitions such as injecting drug us- ers, heroin or opiate users. Even though RELIS software does allow to extract data on these subgroups, it targets 'problem drug use' defined as follows: 'Injecting drug use or long duration/regular use of opioids, cocaine and/or amphetamines'.

This definition leads to a second important consideration, namely the use of data gathered through drug use surveillance systems. The national surveillance data on drug misuse are intended to serve policy-making, action planning and resources allocation, building upon the principle that 'Effective drug policy should be based on a systematic and comprehensive assessment of the nature extent and distribution of drug use within a community' [29]. The first aim of drug use surveillance and prevalence studies should be to reach benefits in terms of care for the target population. This target population does not exclusively consist of heroin addicts or drug users in treatment for instance. It is composed of persons encountering diverse problems stemming from their drug use in the first place and potentially also causing damage to the community. Therefore, the case definition of PDU is preferred to more restrictive ones because it arguably provides a more accurate picture of the extent of the problem and its correlates.

The particular question addressed in this paper is to know how to conceive a reliable, construct valid and costeffective battery of tools and methods within the framework of a national drug use surveillance routine to assess the prevalence of PDU. In other words, what are possible ways to arrange the patchwork of mostly scattered data on the extent and the pattern of PDU into a structured, reliable and valid body of evidence? There is presumably no single answer to this question, but it should be possible to investigate relationships between different instruments and methods as well as their respective strengths and weaknesses to assess the robustness of a national drug prevalence estimation procedure and thus the accuracy of its outcome.

\section{Methods}

Serial estimates of problem drug users were obtained by applying the following methods: two-, three- and four-source capturerecapture (CR) based on data from all existing national facilities for detoxification treatment, outpatient substitution treatment, inpatient drug therapy, as well as data on drug users yearly indexed by law enforcement agencies; truncated Poisson regression model (tPm) associated to Zelterman's and Chao's estimators on RELIS contact frequencies and four multiplier computations respectively combining datasets on first drug law offenders and the rate of acute drug death victims known by law enforcement agen- 
cies $(\mathrm{M} 1)^{1}$, on drug use law offenders and the proportion of problem drug users in contact with police (M2), on drug-related death cases and drug-related mortality rates (M3), and on drug treatment admissions and in-treatment rates (M4). CR on two and three sources, tPm, M1 and M2 were performed in all serial studies from 1999 to 2009 respectively on the same sources. Due to the restructuration of the main national psychiatric hospital (CHNP), detoxification treatment has been decentralized within four regional hospitals running psychiatric services, which were included in CR models in 2009 instead of the CHNP.

Estimates of injecting drug users were obtained by multiplying PDU estimates by IDU rates in the national PDU population as provided by RELIS on a yearly basis (P[PDU/IDU]). In order to consolidate the final estimation outcome, a back-calculation method based on HIV data was also applied. The number of HIVinfected injecting drug users has been used as numerator and the proportion of HIV infections among injecting drug users as denominator to estimate the total number of injecting drug users (M[IDU/HIV]). Where appropriate, 95\% CI and mid-point estimates were calculated. Lower and upper bounds of results, as provided by applied methods, were used to set estimation margins.

Data were provided by the national RELIS surveillance system, maintained by the Luxembourg focal point of the EMCDDA. Drug users indexed by RELIS are digitally anonymized by means of an encryption algorithm approved by the National Commission on Data Protection. The thus obtained individual RELIS code allows respondents' recognition within and between sources and to avoiding multiple counts.

Statistical analysis was carried out with SPSS 13.0/19.0 software and GLIM 4 update 9 (for 2003 and 2007 CR computations only). log-linear analysis was used for three- and four-source CR computations. CR models were compared using the log likelihood ratio $\left(\mathrm{G}^{2}\right)$, the Aikaike's information criterion (AIC) [30] and the bayesian information criterion (BIC) [31]. The simplest models with the lowest AIC and BIC scores were retained in case any more complex model with a significantly lower $\mathrm{G}^{2}$ was observed.

\section{Results}

Table 1 shows estimates of problem and injecting drug users as calculated by applied methods. Results provided by different methods show reasonable inter-estimate margins per year, varying from 400 to 743 persons between 1997 and 2009, excluding estimates derived from the tPm Zelterman estimator. As a matter of fact, the Zel-

1 Calculated for the average duration of drug dependence of the target population. Duration of dependence being a routine item of the RELIS surveillance protocol, 10 and 11 years were determined and applied for 1999/2000/2009 and 2007 respectively. Data on first offenders and acute drug deaths have been extracted from the national registers on drug law offenders and on drug-related deaths. Toxicological evidence allowed to determine that all included overdose cases showed ante-mortem heroin and/or cocaine and/or amphetamines consume. Heroin use was detected in almost all cases. Three indexed victims, on transit and not residents of Luxembourg, were excluded. terman estimator provides the highest estimates for all years except for 2009, thus not reflecting, likewise the M2 estimates, the serial prevalence trend line documented by all other methods. Capture-recapture methods on two, three and four sources, $\mathrm{tPm}$ and M1 provided the most consistent PDU estimates. tPm Chao's estimator tend to bring up lower-bound estimates and M2 to provide highest serial estimates.

Until 2003, serial IDU estimates provided by the $\mathrm{P}$ (PDU/IDU) method were higher than those derived from M(IDU/HIV), but observed differences are reasonably small, varying between 20 and 310 persons.

Table 2 provides an overview of mean PDU and IDU prevalence estimates as calculated by different methods and sources, associated 95\% CIs and prevalence rates per 1,000 inhabitants in the total national population and in the population aged 15-64 years.

The latest serial estimate (2009 data) provided a mean prevalence of 2,070 (median 2,094) problem drug users at the national level (95\% CI 1,553-2,623). In terms of prevalence rates, 4.19/1,000 and 6.16/1,000 inhabitants out of the general population and aged between 15 and 64 years respectively show PDU. The number of injecting drug users was estimated at 1,907 persons representing an IDU prevalence rate of 5.68/1,000 inhabitants aged between 15 and 64 years.

According to serial estimates performed between 1997 and 2009 (fig. 1), absolute prevalence and prevalence rates of PDU showed an increasing trend until 2000. After a brief stabilization phase, a downward trend, observed from 2003 onwards, was confirmed by most applied methods. Absolute prevalence of IDU, however, increased between 1997 and 2007, and so had the IDU prevalence rate in the national population aged 15-64. Data for 2009 show a decrease in IDU prevalence that should, however, be interpreted only in the light of future serial data.

\section{Discussion}

We conducted a serial, multi-method/multi-source prevalence study on problem and injecting drug users in Luxembourg, applying various estimation techniques based on data provided by the national drug use surveillance system (RELIS). We then confronted serial estimates, provided by comparable methodologies allowing to follow-up the evolution of national PDU and IDU prevalence over a period of 13 years between 1997 and 2009.

Serial estimates suggest that even though the absolute number of problem drug users has not been increasing 
for several years, the needs in terms of prevention, care and treatment have nonetheless changed to a large extent. The high and increasing rate of polydrug use in problem drug users (2007) and the increasing number of drugrelated death cases during the referred period [32] tend to corroborate this statement. In other words, a seemingly decreasing number of drug users appear to have developed more hazardous and care-demanding consume pattern. This is an important observation since it shows that prevalence data might allow to assess the size of a population but not necessarily the extent of a problem and its correlates.

A detailed comparative analysis of single estimates revealed that capture-recapture models are valuable tools for drug prevalence estimation and its methodological constraints have been thoroughly described in the literature [1-8]. Accordingly, a fundamental application assumption of CR requires the studied population to be closed; there should be no movement into or out of the population during the study period. Obviously, applied to problem drug users, this condition is unlikely to be fully met as some of them might die, relapse, quit or newly join the PDU population during the study. A capture-recapture period limited to 1 year was therefore chosen to reduce potential bias introduced by the violation of the 'closed population assumption'.

A second important assumption regards homogeneity of the study population; each individual should have the same probability of being present in each source. The likelihood of being indexed, however, relies on individual factors such as severity of drug dependence in association with increased risk behavior, socioeconomic status [33], current treatment or incarceration status as well as on structural factors such as differences in availability or accessibility of existing treatment facilities.

Since Luxembourg stands for a rather small territory and the PDU population is concentrated in two major cities where demand reduction and supply reduction offers and measures were comparable and stable between 1997 and 2009, the impact of structural factors should be limited. On the other hand, easy and payment-free access to national treatment offers may result in increased treat-

Table 1. Estimates of absolute prevalence of PDU and IDU in Luxembourg, 1997-2009

\begin{tabular}{|c|c|c|c|c|c|c|}
\hline PDU estimates - method: captur & apture & & & & & \\
\hline CR 2 sources & & & & & & \\
\hline $\mathrm{P}^{1999} \& \mathrm{M}^{1999}$ & 1999 & l & 700 & 1,375 & 2,075 & $1,587-2,563$ \\
\hline $\mathrm{P}^{2000} \& \mathrm{M}^{2000}$ & 2000 & l & 636 & 1,980 & 2,616 & $1,801-3,431$ \\
\hline $\mathrm{P}^{2003} \& \mathrm{M}^{2003}$ & 2003 & l & 574 & 1,816 & 2,390 & $1,966-2,814$ \\
\hline $\mathrm{P}^{2009} \& \mathrm{HO}^{2009}$ & 2009 & l & 371 & 1,485 & 1,856 & $1,016-2,696$ \\
\hline \multicolumn{7}{|l|}{ CR 3 (1) sources } \\
\hline $\mathrm{H}^{1999} \& \mathrm{P}^{1999} \& \mathrm{M}^{1999}$ & 1999 & $\begin{array}{l}\mathrm{H}^{1999 *} \mathrm{P}^{1999} \\
\mathrm{H}^{1999 *} \mathrm{M}^{1999}\end{array}$ & 664 & 1,663 & 2,327 & $1,510-3,926$ \\
\hline $\mathrm{H}^{2003} \& \mathrm{P}^{2003} \& \mathrm{M}^{2003}$ & 2003 & $\mathrm{H}^{2003 *} \mathrm{P}^{2003}$ & 594 & 2,051 & 2,645 & $1,871-3,986$ \\
\hline $\mathrm{H}^{2007} \& \mathrm{P}^{2007} \& \mathrm{M}^{2007}$ & 2007 & $\mathrm{H}^{2007 *} \mathrm{P}^{2007}$ & 497 & 2,114 & 2,611 & $1,703-4,401$ \\
\hline $\mathrm{P}^{2003} \& \mathrm{M}^{2003} \& \mathrm{~T}^{2003}$ & 2003 & Independence & 505 & 2,043 & 2,548 & $1,773-3,911$ \\
\hline $\mathrm{P}^{2007} \& \mathrm{M}^{2007} \& \mathrm{~T}^{2007}$ & 2007 & Independence & 491 & 1,699 & 2,190 & $1,567-3,244$ \\
\hline \multicolumn{7}{|l|}{ CR 4 sources } \\
\hline $\mathrm{H}^{2000} \& \mathrm{P}^{2000} \& \mathrm{~T}^{2000} \& \mathrm{M}^{2000}$ & 2000 & $\begin{array}{l}\mathrm{H}^{1999 *} \mathrm{P}^{1999} \\
\mathrm{H}^{1999 *} \mathrm{~T}^{1999} \\
\mathrm{P}^{2000 *} \mathrm{~T}^{2000} \\
\mathrm{~T}^{2000 *} \mathrm{M}^{2000}\end{array}$ & 719 & 2,156 & 2,875 & $2,156-3,948$ \\
\hline $\mathrm{H}^{2003} \& \mathrm{P}^{2003} \& \mathrm{~T}^{2003} \& \mathrm{M}^{2003}$ & 2003 & $\mathrm{P}^{2003 *} \mathrm{H}^{2003}$ & 629 & 1,827 & 2,456 & $1,825-3,466$ \\
\hline $\mathrm{H}^{2007} \& \mathrm{P}^{2007} \& \mathrm{~T}^{2007} \& \mathrm{M}^{2007}$ & 2007 & $\mathrm{P}^{2007 *} \mathrm{H}^{2007}$ & 534 & 1,644 & 2,178 & $1,595-3,131$ \\
\hline
\end{tabular}


Table 1 (continued)

\begin{tabular}{|c|c|c|c|c|c|}
\hline Estimator & Year & $\begin{array}{l}\text { Total } \\
\text { observed }\end{array}$ & $\begin{array}{l}\text { Hidden population } \\
\text { (estimation) }\end{array}$ & $\begin{array}{l}\text { Total } \\
\text { population }\end{array}$ & $95 \% \mathrm{CI}$ \\
\hline \multicolumn{6}{|c|}{ PDU estimates - method: truncated Poisson model (tPm) - Zelterman \& Chao estimators ( 1 source) } \\
\hline \multirow{3}{*}{ Zelterman est. (Zn) } & 2000 & 783 & 2,141 & 2,924 & $2,710-3,176$ \\
\hline & 2003 & & & 3,206 & $2,880-3,537$ \\
\hline & 2007 & & & 3,175 & $2,780-3,786$ \\
\hline \multirow[t]{5}{*}{ Chao est. (Cn) } & 1999 & 744 & 1,333 & 2,077 & $1,912-2,290$ \\
\hline & 2000 & 783 & 1,349 & 2,132 & $1,968-2,342$ \\
\hline & 2003 & & & 2,332 & $2,105-2,621$ \\
\hline & 2007 & & & 2,470 & $2,146-2,890$ \\
\hline & 2009 & 779 & 944 & 1,723 & $1,496-2,022$ \\
\hline \multicolumn{6}{|c|}{ PDU estimates - method: benchmark multipliers } \\
\hline \multirow{4}{*}{\multicolumn{3}{|c|}{ Law enforcement data/drug-related death data }} & 1999 & 2,350 & $2,209-2,483$ \\
\hline & & & 2003 & 2,650 & $2,587-2,721$ \\
\hline & & & 2007 & 2,515 & $2,347-2,681$ \\
\hline & & & 2009 & 2,166 & $1,994-2,338$ \\
\hline \multicolumn{6}{|l|}{ M2 } \\
\hline \multirow{5}{*}{\multicolumn{3}{|c|}{ Law enforcement data/law enforcement contact rate }} & 1997 & 2,300 & I \\
\hline & & & 1999 & 2,624 & 1 \\
\hline & & & 2003 & 2,008 & 1 \\
\hline & & & 2007 & 2,220 & 1 \\
\hline & & & 2009 & 2,340 & I \\
\hline \multirow{4}{*}{ Method: P(IDU/PDL } & & & 2000 & 1,920 & 1 \\
\hline & & & 2003 & 1,755 & I \\
\hline & & & 2007 & 1,924 & I \\
\hline & & & 2009 & 1,524 & \\
\hline \multirow[t]{6}{*}{ Method: M(IDU/HI } & & & 1997 & 1,582 & I \\
\hline & & & 1999 & 1,686 & 1 \\
\hline & & & 2000 & 1,610 & I \\
\hline & & & 2003 & 1,735 & I \\
\hline & & & 2007 & 2,422 & I \\
\hline & & & 2009 & 2,301 & 1 \\
\hline
\end{tabular}

${ }^{a} \mathrm{CHNP}(\mathrm{H})=$ clients registered by main national detoxification unit; Hospitals $(\mathrm{HO})=$ all national hospitals providing detoxification treatment; SPJ $(\mathrm{P})$ = drug users indexed by national law enforcement agencies; CTM $(\mathrm{T})=$ inpatient drug therapy clients nationwide; $\mathrm{MP}(\mathrm{M})$ = outpatient substitution treatment demanders indexed nationally by specialized agencies; PDU = problem drug users; IDU = injecting drug users. 
Table 2. Absolute prevalence and prevalence rates according to selected subgroups in Luxembourg, 1997-2009

\begin{tabular}{|c|c|c|c|c|c|c|}
\hline & 1997 & 1999 & 2000 & 2003 & 2007 & 2009 \\
\hline \multicolumn{7}{|l|}{ General population } \\
\hline National population on 1st January & 418,300 & 429,200 & 435,700 & 448,300 & 476,200 & 493,500 \\
\hline National population aged $15-64$ years on 1 st January & 281,100 & 287,100 & 291,000 & 300,800 & 322,000 & 336,015 \\
\hline \multicolumn{7}{|l|}{ Problem drug users } \\
\hline PDU mean prevalence & 2,100 & 2,350 & 2,625 & 2,530 & 2,470 & 2,070 \\
\hline Mean 95\% CI & $1,900-2,300$ & $1,994-2,758$ & $2,246-3,295$ & $2,144-3,293$ & $1,945-3,343$ & $1,553-2,623$ \\
\hline Total mean prevalence rate & $5 / 1,000$ & $5.48 / 1,000$ & $6.02 / 1,000$ & $5.64 / 1,000$ & $5.19 / 1,000$ & $4.19 / 1,000$ \\
\hline Total mean prevalence rate (age $15-64$ ) & $7.47 / 1,000$ & $8.19 / 1,000$ & $9.02 / 1,000$ & $8.41 / 1,000$ & $7.67 / 1,000$ & $6.16 / 1,000$ \\
\hline \multicolumn{7}{|l|}{ Injecting drug users } \\
\hline IDU mean prevalence & 1,656 & 1,757 & 1,765 & 1,745 & 2,173 & 1,907 \\
\hline Estimate margins & $1,528-1,785$ & $1,686-1,828$ & $1,610-1,920$ & $1,735-1,755$ & $1,924-2,422$ & $1,524-2,301$ \\
\hline Total mean prevalence rate & $3.96 / 1,000$ & $4.09 / 1,000$ & $4.05 / 1,000$ & $3.89 / 1,000$ & $4.56 / 1,000$ & $3.86 / 1,000$ \\
\hline Total mean prevalence rate (age $15-64$ ) & $5.89 / 1,000$ & $6.12 / 1,000$ & $6.07 / 1,000$ & $5.80 / 1,000$ & $6.75 / 1,000$ & $5.68 / 1,000$ \\
\hline
\end{tabular}

Fig. 1. Absolute prevalence estimates of PDU and IDU, Luxembourg, 1997-2009 [1]. CR2/CR3/CR4 = Capture-recapture methods on two, three and four sources. M1 = Multiplier method: police and drugrelated deaths registers; M2 = multiplier method: number of drug law offenders/ law enforcement contact rate of drug offenders; M3 = multiplier method: number of fatal overdose cases/drug-related mortality rate; $\mathrm{M} 4$ = extrapolation from treatment data. $\mathrm{P}(\mathrm{IDU} / \mathrm{PDU})=$ Multiplier method: PDU estimates/IDU rates; $\mathrm{M}(\mathrm{IDU} / \mathrm{HIV})=$ multiplier method: number of HIV-infected IDU/rate of HIV infections among IDU.

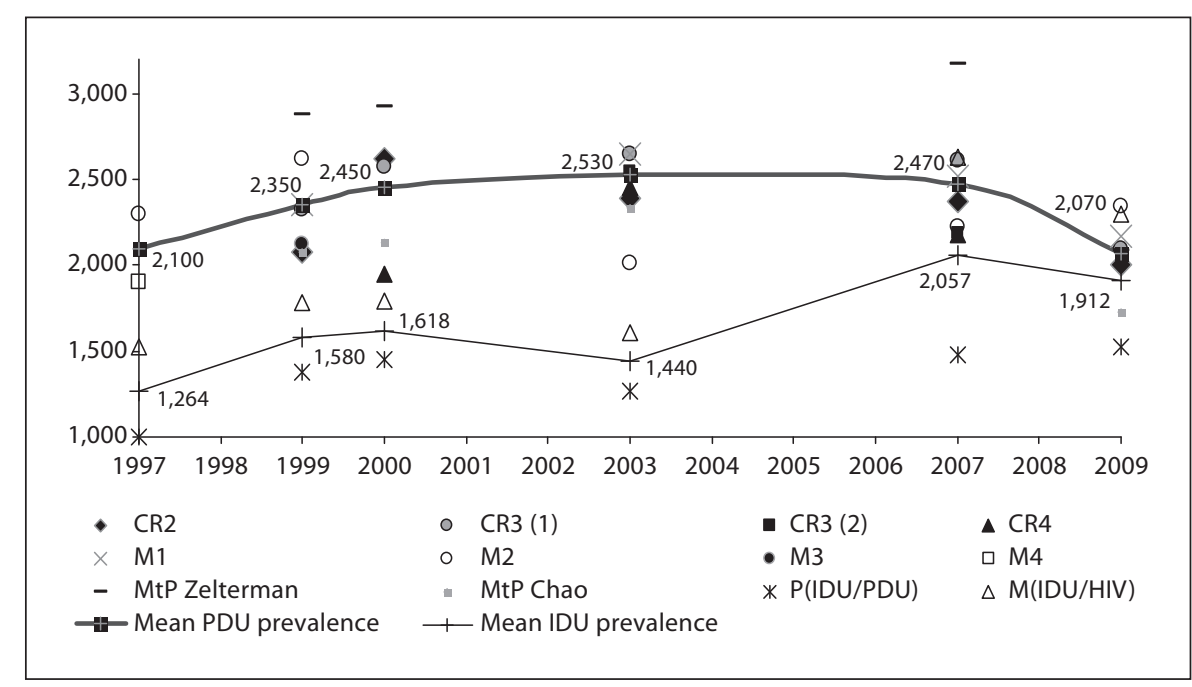

ment rotation by patients. In order to assess the homogeneity of the target population, we performed a comparison of the sum of estimations applied to gender-stratified samples with the total estimation performed on nonstratified samples. As the results obtained by both approaches were highly similar, homogeneity of the study population could be reasonably assumed.

The homogeneity assumption appears to be related to an additional condition requiring that being present in one source should not affect the probability of being in another source. A positive dependence between two sources included in the CR model would result in an underestimation of the total population, and vice versa. To reduce the potential impact of a violation of the mutual independence assumption, both supply and demand re- duction sources were included in the CR models. Furthermore, sources linked to each other by agreed, routine or systematic referral procedures were not combined for the same reason. Ultimately, it should be stressed that CR analysis including more than two sources accounts for potential dependences between selected sources in the selection of best-fitted regression models.

The truncated Poisson model (tPm) may be seen as a particular application of a CR model, based on a single data source. Also, a 'drug use-related institutional contact' can be described as being a rare event, following a Poisson-shaped distribution [34]. Matching observational data with a Poisson distribution thus allows estimating the number of persons that have not been indexed in a given setting or database, hence representing the hidden 
population. The applicability of the tPm relies on the same assumptions as CR models, although the independence condition is specific as it assumes that an individual does not show a behavioral response to being indexed at least once. The particularity of the tPm model applied in this study lies in the fact that frequency data were provided by the RELIS database, indexing all national drugrelated contacts with both drug demand or drug supply reduction institutions. All sources included in RELIS, and previously described, have thus been aggregated into a single national and highly representative dataset on drug-related institutional contacts.

Available data also allowed applying a series of multiplier methods. The 'first offender - mortality' method (M1) builds upon the number of first drug law offenders (for drug use) during a time window equal to the average duration of dependence of national problem drug users (A), the number of acute drug deaths during the same period (B) and the respective number of acute drug deaths having been registered as problem drug users previously (C) to provide the total number of problem drug users $(\mathrm{T})=\mathrm{A} \times \mathrm{B} / \mathrm{C}$. The average duration of drug dependence has been calculated for each study year on the basis of national RELIS data, which reduced the bias that may result from the application of international literature-based dependence duration estimates. Moreover, M1 has been applied by including all drug-related deaths cases (direct and indirect ${ }^{2}$ ) and results were similar to the ones obtained by using acute cases only. As can be seen in table 1, both estimates have been used as upper and lower bounds of estimates calculated by applying M1.

Due to the representativeness of collected data, described precautions to reduce potential bias and the consistency of estimates with results provided by other estimation methods, it can be assumed that the described method (M1) is a valuable tool to estimate PDU prevalence in Luxembourg. The fact that dependence duration can be accurately determined generally via both monitoring and survey data, and that annual variations in the number of reported drug offenders and drug-related deaths cases have less impact on a given year estimation since both represent multi-annual sums in the final equation, makes this method, as applied, a presumably robust and generally recommendable instrument to estimate drug misuse prevalence.

\footnotetext{
2 Indirect drug-related deaths include known problem drug users who died from accidents under the influence of illicit drugs, suicide, drug-related infectious diseases or consequences of long-term abuse. Aggregated data were provided by the police.
}

The second applied multiplier method (M2) also relies on police data as it estimates the total PDU prevalence by dividing the number of registered problem drug users in a given year by the proportion of problem drug users having reported previous contact with law enforcement. Contact with law enforcement is a standard item of the national RELIS data protocol and thus allows calculating contact rates on a yearly basis and applying them selectively for each serial estimate. However, this method is sensitive to the yearly number of registered offenders that may differ greatly according to law enforcement activity and changes in supply reduction strategies.

Likewise, the mortality multiplier method (M3), though one of the simplest ways to estimate the prevalence of drug misuse, is highly sensitive to variations in drug-related mortality rates (e.g. HIV/AIDS epidemics, high purity or contamination of street drugs). This is even more so when the absolute yearly number of drugrelated deaths is relatively small as is the case in Luxembourg. Even slight changes in mortality, not necessarily due to a change in the size of the population at risk, may have a significant bias impact on estimation results. For that reason, and the fact that no national mortality rates were available after 1999, this specific method could not be applied on a serial basis.

The last multiplier method (M4) also relies on a benchmark (problem drug users in treatment during a given year), available at the national level and a multiplier (intreatment rate of problem drug users). As the latter has not been estimated by any national study since 1997, the referred method could not be applied in following years.

IDU prevalence estimates have been calculated using two methods. The P(IDU/PDU) method is straightforward but its outcome should be considered with caution since it relies on two further estimates that are: the estimated number of problem drug users and the proportion of injecting drug users in the national PDU population.

The M(IDU/HIV) method is obviously more sophisticated and demanding in terms of data input, but its accuracy largely depends on the proportion of HIV-infected injecting drug users not (yet) diagnosed and the reliability of provided HIV rates in injecting drug users (e.g. self-reported or serology-based data). In countries such as Luxembourg, where the HIV epidemic in drug users is small, even slight changes in the denominator have great impact on the estimation result (e.g. a change in the HIV infection rate in problem drug users from 2 to $4 \%$ will result in an estimation decreased by $100 \%)$. Moreover, the numerator varies according to the impact of new treatment options on the mortality of HIV-infected problem 
drug users for instance. Especially in a longitudinal perspective, it is crucial that the epidemic remains structurally more or less stable.

The fact that, in contrast to previous years, the 2007 and 2009 upper bound estimates, obtained via M(IDU/ HIV), appear to be consistently higher than the P(IDU/ PDU)-based estimation, may stem from the fact that from 2004 onwards the absolute yearly number of HIV-infected persons (which sum is multiplied by the proportion of HIV-seropositive persons infected via IDU to obtain a proxy for the total number of HIV-infected injecting drug users) has been increasing, whereas the proportion of injecting drug users within the HIV-infected population has been showing a decreasing trend, partially due to welldocumented [35] improvements in national harm reduction offers. Hence, having advanced knowledge of the national HIV/AIDS epidemic is of utmost importance when applying the referred method, especially when small figures are at stake. These observations also underline the need to confront obtained single estimations to results from other methods and indirect indicators.

A national drug use surveillance system, based on different (DR and SR) sources and settings, referred to as 'institutional contact indicator' in the present paper, and able to exclude multiple counts, appears to be a valuable instrument to estimate PDU and IDU prevalence and to consolidate these by a multi-method approach. National PDU estimation based on a single method should be avoided as the present study showed that for different years all applied methods may provide upper and lower bound estimates.

The framework of a national drug use surveillance system, based upon standardized and time-persistent data collection routines may reduce bias produced by external factors and cross-sectional data for instance - especially in the context of serial estimations and trends surveillance. The application of CR methods is feasible and particularly indicated if these surveillance systems build upon case-exhaustive sources. Selected multiplier methods may be applied via surveillance data if a series of pertinent items are included in the routine protocol (i.a. law enforcement contacts, HIV status, duration of dependence). Most multiplier methods, however, need additional data from other sources (e.g. mortality rate, in-treatment rate, proportion of HIV-infected problem drug users), which may impede their application.

This said, IDU and PDU prevalence estimates should be primary based on 'hard' data and methodologies least relying on specific rates, multipliers or preliminary estimates. Capture-recapture methods, tPms, applied on the national PDU population showing institutional contact, and the M1 multiplier method, based on longitudinal data, showed to be applicable and most reliable in the context of PDU prevalence estimations. As a matter of fact, the latter methods seem to provide best input for consolidated PDU prevalence estimates but only to the extent that external and structural factors, not resulting from an actual increase of the population at risk (i.e. changes in treatment options or access, HIV outbreak, increased mortality due to quality variations in street drugs, changes in data quality), can be assumed to be stable.

Sound knowledge of the national drugs problem and its correlates is crucial when it comes to take appropriate decisions on the accuracy of a given prevalence estimation method and its results. Routine and serial application of a selected battery of estimation methods can be a valuable tool for drug misuse surveillance. If the choice of various methods to be best applied in a given national context largely depends on the availability, quality and consistency of required data, the methodological issues addressed in the present paper may serve the final decision making.

Further research should also investigate more dynamic ways to describe PDU and integrate recent findings on entry and cessation rates applied to hard drug use [36] as well as the possible associations between indirect trend indicators (e.g. drug-related mortality, seizures, service usage, treatment demand) and the prevalence of drug misuse in a longitudinal perspective in order to fine-tune, complement and further validate nationally applied prevalence estimations of drug misuse and thus contribute to enhance evidence based drug policy planning.

\section{Acknowledgements}

Thanks are due to Gordon Hay (Centre for Drug Misuse Research University of Glasgow) and Filip Smit (Trimbos Institute Netherlands Institute of Mental Health and Addiction) for their statistical support, to Sofia Lopes da Costa, Pascale Straus and Celine Diederich (EMCDDA Focal Point Luxembourg/CRP-Santé) for their relentless efforts to ensure and maintain quality of data provided by the national RELIS surveillance system, to all participating agencies and services of the RELIS network, to the EMCDDA for its valuable work on the PDU indicator as well as its efforts to further develop quality standards and especially to Danica Klempova (EMCDDA) for her support.

\section{Disclosure Statement}

The author has no conflicts of interest to disclose. 


\section{References}

1 European Monitoring Centre for Drugs and Drug Addiction (EMCDDA): Methodological guidelines to estimate the prevalence of problem drug use at local level. CT.97.EP.05. Lisbon, EMCDDA, 2000.

$>2$ International Working Group for Disease Monitoring and Forecasting: Capture-recapture and multiple record systems estimation: history and theoretical development. Am J Epidemiol 1995;142:1047-1057.

-3 Frischer M, Hickman M, Kraus L, Mariani F, Wiessing L: A comparison of different methods for estimating the prevalence of problematic drug misuse in Great Britain. Addiction 2001;96:1465-1476.

4 Brecht ML, Wickens TD: Application of multiple capture methods for estimating drug use prevalence. J Drug Issues 1993;23: 229-250.

-5 Larson A, Stevens A, Wardlaw G: Indirect estimates of 'hidden' populations: capture-recapture methods to estimate the numbers of heroin users in the Australian Capital Territory. Soc Sci Med 1994;39:823-831.

-6 Hickman M, Stimson G, Howe S, Farrell M, Taylor C, Cox S, et al: Estimating the prevalence of problem drug use in inner London: a discussion of three capture-recapture studies. Addiction 1999;94:1653-1662.

7 Maxwell JC: Methods for estimating the number of hard core drug users. Subst Use Misuse 2000;35:399-420.

$>8$ Brodsky MD: History of heroin prevalence estimation techniques. NIDA Res Monogr 1985;57:94-103.

-9 Frank B, Schmeidler J, Johnson B, Lipton DS: Seeking truth in heroin indicators: the case of New York City. Drug Alcohol Depend 1978;3:345-358.

10 Hartnoll R, Lewis R, Mitcheson M, Bryer S: Estimating the prevalence of opioid dependence. Lancet 1985;1:203-205.

11 Hall W, Ross J, Lynskey M, Law M, Degenhardt L: How many dependent heroin users are there in Australia? Med J Aust 2000;73: 528-531.

12 Choi YH, Chomiskey CM: Methods for providing the first prevalence estimates of opiate use in Western Australia. Int J Drug Policy 2003;14:297-305.
13 Hay G, Smit F: Estimating the number of drug injectors from needle exchange data. Addiction research and theory. Addiction 2001;96:1465-1476.

14 Rhodes W: Synthetic estimation applied to the prevalence of drug use. J Drug Issues 1993;23:297-322.

15 Wickens TD: Quantitative methods for estimating the size of a drug-using population. J Drug Issues 1993;23:185-216.

16 Hser Y-I, Prendergast M, Anglin MD, Chen JK, Hsieh S-C: A regression analysis estimating the number of drug-using arrestees in 185 US cities. Am J Public Health 1998;88: 487-490.

17 Mariani F, Guaiana R, Di Fiandra T: An epidemiological overview of the situation of illicit drug abuse in Italy. J Drug Issues 1994; 24:579-595.

18 Kraus L, Augustin R, Frischer M, Kümmler $\mathrm{P}$, Uhl A, Wiessing L: Estimating prevalence of problem drug use at national level in countries of the European Union and Norway. Addiction 2003;98:471-485.

19 Smit F, Toet J, van Oers H, Wiessing L: Estimating local and national problem drug use prevalence from demographics. Addict Res Theor 2003;11:401-413.

20 Greene MH: Estimating the Prevalence of Heroin Use in a Community. Washington, Special Office for Drug Abuse Prevention, 1974.

21 World Health Organization/Mental Health and Substance Dependence Department: Guide to Drug Abuse Epidemiology. Geneva, WHO, 2000, pp 249-321.

22 Stauffacher M: Drug treatment data as an epidemiological indicator: methodological considerations and improved analysis. Bull Narcot 2002;54:73-85.

23 Hartnoll LR: Drug epidemiology in the European institutions: historical background and key indicators. Bull Narcot 2003;55:5371.

24 Origer A: Procedures to avoid double counting in drug treatment reporting systems; in Simon R, Donmall M, Hartnoll R, et al (eds): The EMCDDA/Pompidou Group Treatment Demand Indicator Protocol: a European core item set for treatment monitoring and reporting. Eur Addict Res 1999;5:197-207.
25 Kimber J, Hickman M, Degenhardt L, Coulson T, van Beek I: Estimating the size and dynamics of an injecting drug user population and implications for health service coverage: comparison of indirect prevalence estimation methods. Addiction 2008; 103: 1604-1613.

26 United Nations Office on Drugs and Crime/ Global Assessment Programme on Drug Abuse: Estimating prevalence: indirect methods for estimating the size of the drug problem. Toolkit Module 2. UNODC 2003; 66.

27 European Monitoring Centre for Drugs and Drug Addiction: 2007 Annual Report on the State of the Drugs Problem in Europe. Lisbon, EMCDDA, 2007.

28 European Monitoring Centre for Drugs and Drug Addiction. Insights Series No. 9: Assessing Illicit Drugs in Wastewater. Potential and Limitations of a New Monitoring Approach. Lisbon, EMCDDA, 2008, pp 80-89.

29 Frischer M: Estimating the Prevalence of Drug Misuse in Scotland: A Critical Review and Practical Guide. Edinburgh, The Scottish Office, 1996.

30 Akaike H: A new look at the statistical model identification. IEEE Transact Automat Control 1974;19:716-723.

-31 Schwarz GE: Estimating the dimension of a model. Ann Statist 1978;6:461-464.

32 Origer A: Annual report on the state of the drugs problem in the Grand Duchy of Luxembourg, 2007. Luxembourg, Centre de Recherche Public-Santé/NFP, 2008.

33 Galea S, Vlahov D: Social determinants and the health of drug users: socioeconomic status, homelessness, and incarceration. Public Health Rep 2002;117(suppl 1):135-145.

-34 Hser YI: Population estimation of illicit drug users in Los Angeles County. J Drug Issues 1993;23:323-334.

35 Trimbos Instituut: Evaluation of the National Drug Action Plan (2005-2009) of Luxembourg. Utrecht, Netherlands Institute of Mental Health and Addiction, 2009.

-36 Amundsen EJ. Bretteville-Jensen AL, Kraus L: A method to estimate total entry to hard drug use: the case of intravenous drug use in Norway. Eur Addict Res 2011;17:129-135. 